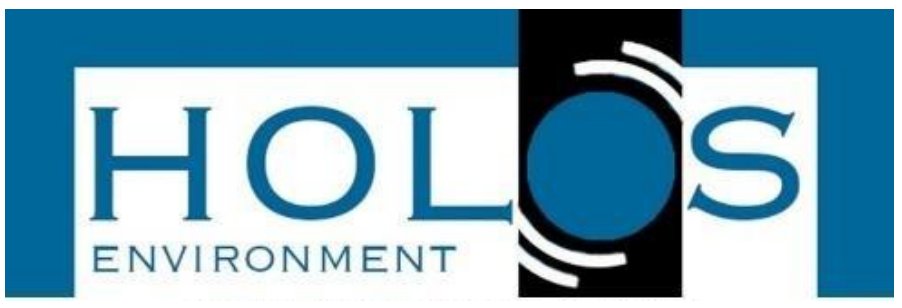

\title{
DECOMPOSIÇÃO FOLIAR DA SERAPILHEIRA DE DOIS SISTEMAS AGROFLORESTAIS NO CERRADO SUL-MATO-GROSSENSE
}

\section{LEAF LITTER DECOMPOSITION OF TWO AGROFORESTRY SYSTEMS IN THE CERRADO SUL-MATO-GROSSENSE}

\author{
Vilma Portilho de Assis ${ }^{1}$; Poliana Ferreira da Costa ${ }^{1}$; Mylena dos Santos ${ }^{1}$; Caroline Quinhones \\ Fróes ${ }^{2}$; Maíra Cristina de Oliveira Silva ${ }^{3}$
}

Artigo recebido em: 22/06/2020 e aceito para publicação em: 15/08/2020.

DOI: http:/dx.doi.org/10.14295/holos.v20i4.12405

\begin{abstract}
Resumo: Um dos indicadores importantes para um ecossistema é a serapilheira, pois ela fornece nutrientes e matéria orgânica que são essenciais para o funcionamento do ambiente. Assim sendo, o objetivo deste estudo foi avaliar a taxa de decomposição foliar da serapilheira e correlacioná-la com índices meteorológicos, em duas áreas com sistemas agroflorestais (SAF1) formado por diversas espécies de plantas e (SAF2) formado por Heveicultura e abacaxi, em uma região de Cerrado, no município de Pedro Gomes, MS. Para avaliação da decomposição da serapilheira folhas recém-caídas foram coletadas das áreas de estudo e transferidas à estufa por 96 horas. Em seguida, foram pesadas frações de 10 gramas e inseridas em litterbags. Foram alocados 20 litterbags em cada área de estudo e a remoção das amostras ocorreu aos 30, 60, 90 e 120 dias, retirando-se 5 amostras por área e época avaliada. Foi estimada a massa foliar remanescente dos litterbags, o tempo de meia vida ( $t$ 1 $1 / 2$ ) e a constante de decomposição $(k)$. Posteriormente, a correlação de Pearson ( $r$ ) entre as variáveis climáticas e $\mathrm{k}$. A perda da massa foliar foi maior na área do SAF2, e em ambas as áreas a temperatura e precipitação tiveram influência na decomposição foliar da serapilheira.
\end{abstract}

Palavras-chave: Degradação foliar. Influência climática. Precipitação. Temperatura; Indicador Ecológico.

\begin{abstract}
One of the important indicators for an ecosystem is litter because it provides nutrients and organic matter that are essential to the functioning of the environment. Thus, the objective was to evaluate the leaf decomposition rate of the litter and to correlate it with meteorological indices in two areas with agroforestry systems (SAF1) formed by several plant species and (SAF2) formed by Heveiculture and pineapple, a cerrado region in the municipality of Pedro Gomes, MS. For evaluation of litter decomposition leaves of the forest floor surface were collected from the study areas, and transferred to the oven dried at $65{ }^{\circ} \mathrm{C}$ for a 96 hours. They were later weighed 10-gram fractions and inserted into litterbags. Were allocated 20 litterbags to each study area and samples were taken at 30,60,90 and 120 days, with 5 samples per area and time evaluated. The remaining leaf mass of the litter bags, the half-life $\left(t \frac{1}{2}\right)$ and the decomposition constant $(k)$ were estimated. Subsequently, Pearson's correlation $(r)$ between climatic variables and $(k)$. leaf mass loss was higher in the SAF 2 area, and both areas temperature and precipitation influenced the litter decomposition.
\end{abstract}

Keywords: Leaf degradation. Climatic influence. Precipitation. Temperature. Ecological Indicator.

\footnotetext{
${ }^{1}$ Universidade Estadual do Mato Grosso do Sul (UEMS), Dourados, MS. E-mails: (vilma.assis.portilho@gmail.com, polianacostagestao@gmail.com, mylenasantospg11@hotmail.com)

2 Prefeitura Municipal de Ponta Porã, Ponta Porã, MS. E-mail: (carolaf@hotmail.com)

${ }^{3}$ Universidade Federal de São Paulo (Unifesp), São Paulo, SP. E-mail: (maira.maidi@gmail.com)
} 


\section{INTRODUÇÃo}

O Cerrado tem um histórico demarcado pela devastação de extensas áreas o que contribui para a degradação ambiental, decorrente principalmente da exploração agropecuária, que vem mudando a paisagem desse bioma com o excesso de desmatamento, compactação do solo, erosão, assoreamento de rios, contaminação da água subterrânea, entre outros, resultando na perda da biodiversidade e comprometimento de serviços ecossistêmicos. (CUNHA et al., 2008).

A recuperação de uma área degradada está diretamente ligada à ciência da restauração ecológica, que tem o objetivo de contribuir com o restabelecimento de um ecossistema alterado por ações antrópicas ou naturais. Quando um ecossistema possuir seus próprios recursos, sem necessitar da intervenção de outros subsídios, ele é considerado recuperado ou restaurado (MMA, 2019).

Nos dias atuais o fator econômico tem se tornado uma peça chave na tomada de decisão, que pode incentivar ou não a restauração de uma área degradada (AMADOR, 2003). Neste sentido, existem os sistemas mais sustentáveis de produção, que trazem benefícios socioeconômicos e ecológicos. Entre eles, estão os sistemas agrícolas consorciados, como os sistemas agroflorestais, caracterizados pela utilização de duas ou mais espécies, sendo ao menos uma lenhosa perene, aliada a espécie(s) de interesse agrícola (LAMÔNICA; BARROSO, 2008), podendo resultar em sistemas agroflorestais biodiversos ou sistemas simplificados, que desempenham um papel fundamental e inovador na restauração, conservação e produção, promovendo serviços ambientais, geração de renda e segurança alimentar dos proprietários rurais (AMADOR, 2003).

Os sistemas agrícolas consorciados são adotados por produtores há séculos, e caracterizam-se pelo cultivo de várias plantas em um mesmo local, que podem ser semeadas ou plantadas na mesma época ou em intervalos de tempo, de modo que possam compartilhar dos mesmos recursos disponibilizados pelo ambiente, fazendo com que exista uma interação entre elas (HERNANI; SOUZA; CECCON, 2019). A técnica potencializa o aproveitamento da água disponível no solo ou do período chuvoso, propicia benefícios como o controle de plantas daninhas e executa um papel importante na cobertura viva e morta do solo, na manutenção da serapilheira e ciclagem de nutrientes (HERNANI; SOUZA; CECCON, 2019). 
O Sistema Agroflorestal é amparado pelo Novo Código Florestal, instituído pela Lei n. 12.651/2012, podendo ser utilizado para restaurar áreas degradadas em Reserva Legal e, em casos excepcionais, Áreas de Preservação Permanente. Em suma, a lei permite o plantio intercalado de espécies nativas de ocorrência regional com exóticas ou frutíferas, desde que a área recomposta com espécies exóticas não exceda 50\% (cinquenta por cento) da área total a ser recuperada (BRASIL, 2012).

A Heveicultura, prática do cultivo da seringueira (Hevea spp.), também é considerada um método de reflorestamento em áreas degradadas. Pereira et al. (2002) ressaltam que a implantação da Heveicultura traz benefícios para a conservação do solo, água e minimiza o efeito estufa por meio da captura de $\mathrm{CO}_{2}$ da atmosfera, além de ser uma planta adaptável ao solo e clima do Cerrado, constituindo-se como uma potencial fonte agrícola para a região. Sua principal utilização é na produção da borracha natural e látex (GONÇALVES et al., 2013) e trata-se de excelente opção para aumentar a renda familiar (PEREIRA et al., 2002). A seringueira, aliada ao consórcio de outra espécie, por exemplo, o abacaxi (Ananas comosus L. Merril), como é o caso do estudo em questão, também pode ser considerada um sistema agroflorestal simplificado.

Um dos importantes indicadores para um ecossistema é a serapilheira, que se trata de uma camada de matéria orgânica encontrada na parte superior do solo, formada pela queda de folhas, caules, frutos e vestígios faunísticos (ANDRADE; TAVARES; COUTINHO, 2003). Quando acumulada no solo se torna um depósito de nutrientes e matéria orgânica essencial para o funcionamento do ambiente, auxiliando na dinâmica da ciclagem de nutrientes (SPERANDIO et al., 2012), no aumento das propriedades físicas, químicas e biológicas do solo, além de fornecer os componentes necessários aos organismos vivos e ser fundamental na proteção do solo, evitando a formação de erosões (ANDRADE; TAVARES; COUTINHO, 2003).

A decomposição da serapilheira resulta na principal fonte de entrada de nutrientes e é extremamente necessária para o sustento e restauração da vegetação do local, sobretudo em solos degradados ou pouco férteis (SILVA, 2009; ANDRADE; TAVARES; COUTINHO, 2003). Dessa forma, ela gera uma grande quantidade de material nutricional para as plantas e sua velocidade de decomposição regula o acumulo de matéria orgânica. A velocidade do processo de decomposição pode ser influenciada por fatores 
climatológicos, como precipitação e temperatura, organismos decompositores presentes no solo e qualidade do substrato (SILVA, 2014).

Estudar a dinâmica da decomposição, bem como os fatores bióticos e abióticos que a influenciam, é essencial para auxiliar na compreensão da trajetória de áreas implantadas.. Nesse sentido, o presente estudo tem o objetivo de analisar a dinâmica da decomposição da serapilheira foliar e correlacionar com índices meteorológicos, em dois sistemas agroflorestais inseridos em área de Cerrado sul-mato-grossense, no município de Pedro Gomes, para o período experimental de junho a outubro de 2019.

\section{MATERIAL E MÉTODOS}

\subsection{Caracterização das áreas de estudo}

As áreas de estudo localizam-se no município de Pedro Gomes - MS, em uma propriedade rural particular denominada Chácara Mamãe, com coordenadas geográficas $18^{\circ}$ 3'58. 09" de latitude Sul e 54 34' 54.19" de longitude Oeste (Figura 01). O mapa foi elaborado no Software Quantum Geographic Information System (QGIS), versão 2.18 .0 e indica as áreas de coleta da serapilheira (SAF1 e SAF2) O município está inserido dentro do bioma Cerrado (IBGE, 2019b), porém uma porção da vegetação é caracterizada pela presença de pastagens plantadas, várzeas e lavouras.

O Sistema Agroflorestal 1 (SAF1), implantado no ano de 2018, possui uma área de 26.880, $243 \mathrm{~m}^{2}$ e trata-se da combinação de duas espécies, sendo elas a seringueira (Hevea Brasiliensis (Will. Ex. A. Juss.) Mull. Arg.) e o abacaxi (Ananas comosus L. Merril), plantadas com espaçamento de 2 metros. Atualmente, o porte das seringueiras é de aproximadamente 20 metros, a área possui um dossel mais aberto e com clareiras, resultando na presença de gramíneas e camada de serapilheira menos espessa que 0 SAF2.

Já o Sistema Agroflorestal 2 (SAF2), implantado no ano de 2008, possui área de $8.787,716 \mathrm{~m}^{2}$ e trata-se de um sistema biodiverso, composto por várias espécies (vide Tabela 1) e que recentemente foi enriquecido (Tabela 2) conforme Santos (2019). O SAF2 possui dossel mais fechado, com pouca entrada de luz, solo coberto por bastante matéria orgânica, camada de serapilheira espessa e presença de gramíneas inferior ao SAF1. 
Figura 1 - Mapa de localização da área de estudo

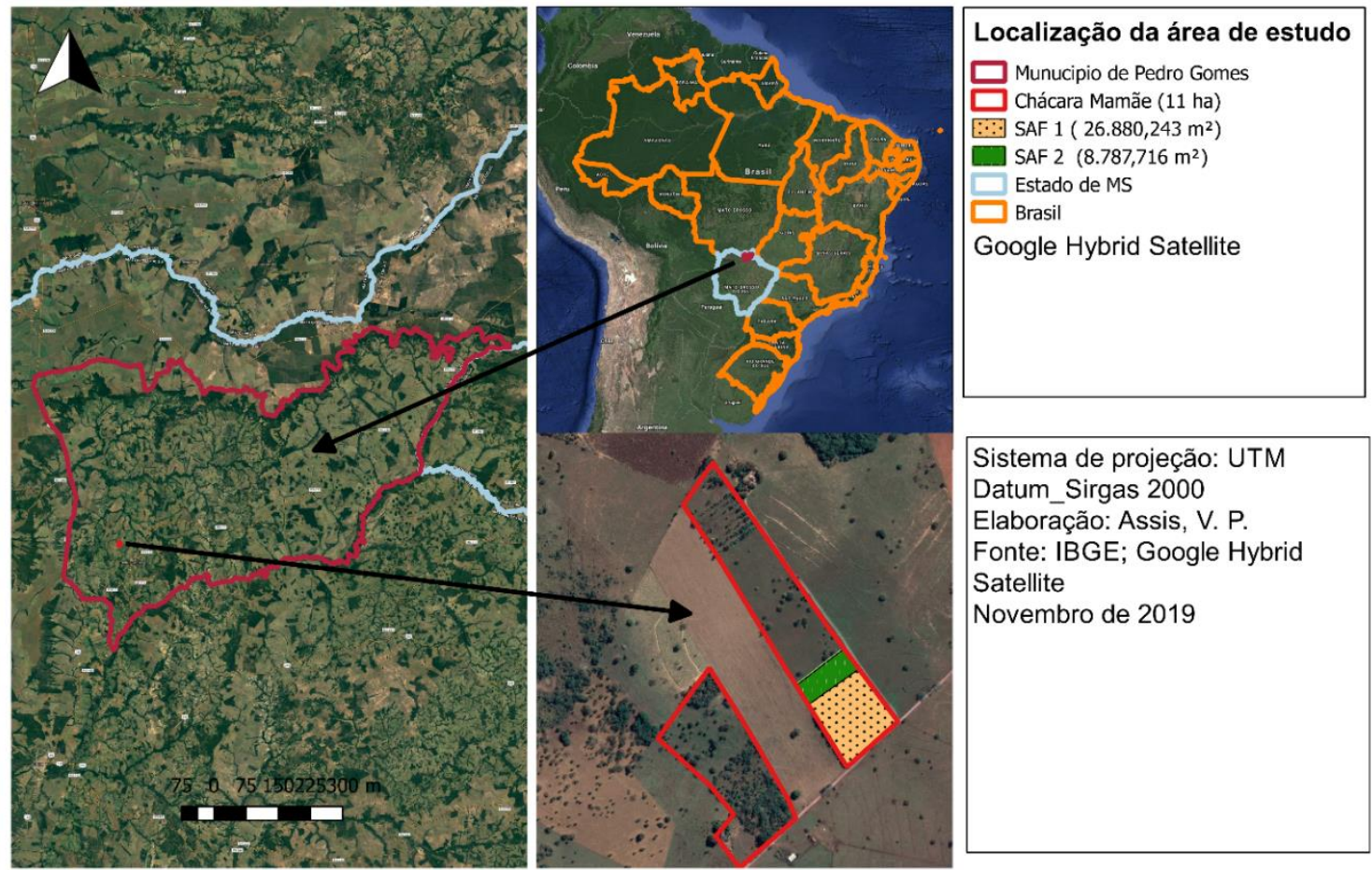

Fonte dos dados: IBGE (2019a) e Google Hybrid Satellite. Elaborado pelas autoras. 
Tabela 1 - Lista das espécies arbustivo-arbóreas amostradas na fitossociologia do Sistema Agroflorestal, espécies existentes no SAF2

\begin{tabular}{|c|c|c|c|c|c|c|c|}
\hline Família & Espécies & Nome Popular & NI & $\mathbf{O}$ & SD & ES & FV \\
\hline \multirow[t]{2}{*}{$\begin{array}{l}\text { ANACARDIACE } \\
\text { AE }\end{array}$} & Astronium fraxinifolium Schott & $\begin{array}{l}\text { Guaritá ou aroeira } \\
\text { d'água }\end{array}$ & 01 & $\mathrm{~N}$ & Ane & $\mathrm{P}$ & A \\
\hline & Schinus terebinthifolia Raddi & Aroeira- vermelha & 02 & $\mathrm{~N}$ & Zoo & $\mathrm{P}$ & $A$ \\
\hline ANNONACEAE & Xylopia aromática (Lam.) Mart. & Pimenta de Macaco & 01 & $\mathrm{~N}$ & Zoo & $\mathrm{P}$ & A \\
\hline ARECACEAE & Acrocomia aculeata (Jacq.) Lodd. Ex Mart. & Macaúba & 01 & $\mathrm{~N}$ & Zoo & $P$ & $A$ \\
\hline \multirow[t]{2}{*}{ BIGNONIACEAE } & Jacaranda cuspidifolia Mart. & Jacarandá de Minas & 11 & $\mathrm{~N}$ & Ane & $\mathrm{P}$ & A \\
\hline & Tabebuia roseoalba (Ridl.) Sandwith & Ipê Branco & 07 & $\mathrm{~N}$ & Ane & ST & A \\
\hline CARICACEAE & Carica papaya L. & Mamoeiro & 02 & $\mathrm{~N}$ & Zoo & SI & Arb \\
\hline $\begin{array}{l}\text { EUPHORBIACE } \\
\text { AE }\end{array}$ & $\begin{array}{l}\text { Hevea Brasiliensis (Wiild. Ex. A. Juss.) Mull. } \\
\text { Arg. }\end{array}$ & Seringueira & 11 & $\mathrm{~N}$ & Aut & ST & A \\
\hline \multirow[t]{2}{*}{ MALVACEAE } & Guazuma ulmifolia Lam. & Chico Magro & 06 & $\mathrm{~N}$ & Zoo & $P$ & $A$ \\
\hline & Sterculia chicha A. St.-Hil. ex Turpin & Chichá & 02 & $\mathrm{~N}$ & Aut & ST & A \\
\hline MORACEAE & Maclura tinctoria (L.) D. Don ex Steud & Amoreira & 11 & $\mathrm{~N}$ & Ane & SI & $A$ \\
\hline MYRTACEAE & Psidium guajava $\mathrm{L}$. & Goiaba Vermelha & 03 & $\mathrm{~N}$ & Zoo & ST & $A$ \\
\hline OPILIACEAE & $\begin{array}{l}\text { Agonandra brasiliensis Miers ex Benth. \& } \\
\text { Hook }\end{array}$ & Quina do Mato & 01 & $\mathrm{~N}$ & Zoo & ST & A \\
\hline RUTACEAE & Zanthoxylum rhoifolium Lam. & Maminha de Porca & 01 & $\mathrm{~N}$ & Zoo & ST & $A$ \\
\hline SAPINDACEAE & Talisia esculenta (A. St - Hil.) Hadlk & Pitomba & 02 & $\mathrm{~N}$ & Zoo & ST & $A$ \\
\hline URTICACEAE & Cecropia pachystachya Trécul & Embaúba & 08 & $\mathrm{~N}$ & Zoo & $\mathrm{P}$ & A \\
\hline
\end{tabular}

$\mathrm{NI}$ : Número de Indivíduos; O: Origem (N - nativa; E - exótica; Cul - cultivada e Nt: - naturalizada); SD: Síndrome de dispersão (Ane - anemocórica; Zoo - zoocórica; Aut- - autocórica); ES: Estágios sucessionais ( $\mathrm{P}$-- pioneira, SI -- secundária inicial, ST -- secundária tardia, SC -- sem caracterização); FV: Forma de Vida (Ep - Epífitas; A - Árvores; At - Arbusto; Li - Liana; H - Herbáacea).

Fonte: Santos (2019). 
Tabela 2 - Lista das espécies arbustivo-arbóreas amostradas no Enriquecimento da Fitossociologia do SAF2.

\begin{tabular}{|c|c|c|c|c|c|c|c|}
\hline Família & Espécies & Nome Popular & NI & $\mathbf{O}$ & SD & ES & FV \\
\hline ANACARDIACE & Astronium fraxinifolium Schott & Guaritá ou aroeira d'água & 06 & $\mathrm{~N}$ & Ane & Sl & A \\
\hline $\mathrm{AE}$ & Schinus terebinthifolia Raddi & Aroeira- vermelha & 03 & $\mathrm{~N}$ & Zoo & $P$ & $A$ \\
\hline APOCYNACEAE & $\begin{array}{l}\text { Hancornia speciosa } \\
\text { Gomes }\end{array}$ & Mangaba & 05 & $\mathrm{~N}$ & Zoo & ST & $A$ \\
\hline \multirow[t]{2}{*}{ BIGNONIACEAE } & $\begin{array}{l}\text { Handroanthus chrysotrichus (Mart. ex DC.) } \\
\text { Mattos }\end{array}$ & Ipê amarelo & 09 & $\mathrm{~N}$ & Ane & SI & A \\
\hline & $\begin{array}{l}\text { Handroanthus } \\
\text { impetiginosus (Mart. ex DC.) Mattos }\end{array}$ & Ipê Roxo ou Piúva & 04 & $\mathrm{~N}$ & Ane & SI & $A$ \\
\hline BIXACEAE & Bixa orellana Linné & Urucum & 06 & $\mathrm{~N}$ & Zoo & $P$ & $A$ \\
\hline $\begin{array}{l}\text { EUPHORBIACE } \\
\text { AE }\end{array}$ & Croton urucurana Baill. & Sangra d'água & 06 & $\mathrm{~N}$ & Aut & $\mathrm{P}$ & A \\
\hline \multirow[t]{3}{*}{ FABACEAE } & Dipteryx alata Vogel & Cumbaru & 6 & $\mathrm{~N}$ & Zoo & ST & $A$ \\
\hline & Inga vera Willd & Ingá do Brejo & 19 & $\mathrm{~N}$ & Zoo & SI & $A$ \\
\hline & Anadenanthera columbrina (vell.) Brenan & Angico Branco & 11 & $\mathrm{~N}$ & Aut & SI & $A$ \\
\hline LAMIACEAE & Vitex montevidensis Cham. & Tarumã & 02 & $\mathrm{~N}$ & Zoo & ST & A \\
\hline LAURACEAE & Persea americana Mill. & Abacate & $-*$ & $\mathrm{Nt}$ & Zoo & ST & A \\
\hline MELIACEAE & Cedrela fissilis Vell. & Cedro & 05 & $\mathrm{~N}$ & Aut & SI & $A$ \\
\hline \multirow[t]{2}{*}{ MYRTACEAE } & Psidium guajava L. & Goiaba Vermelha & 05 & $\mathrm{~N}$ & Zoo & ST & A \\
\hline & $\begin{array}{l}\text { Campomanesia pubescens (Mart. ex DC.) } \\
\text { O.Berg }\end{array}$ & Guavira de Árvore & 06 & $\mathrm{~N}$ & Zoo & ST & A \\
\hline \multirow[t]{2}{*}{ RUBIACEAE } & Alibertia edulis Rich (A. Rich) & Marmelo & 06 & $\mathrm{~N}$ & Zoo & ST & $A$ \\
\hline & Genipa americana L. & Genipapo & 15 & $\mathrm{~N}$ & Zoo & ST & $A$ \\
\hline RUTACEAE & Citrus sinensis (L.) Osbeck & Laranja & $-*$ & $\mathrm{Nt}$ & Zoo & ST & A \\
\hline
\end{tabular}

NI: Número de Indivíduos; O: Origem (N - nativa; E - exótica; Cul - cultivada e Nt: - naturalizada); SD: Síndrome de dispersão (Ane - anemocórica; Zoo-zoocórica; Aut -- autocórica); ES: Estágios sucessionais (P -- pioneira, SI -- secundária inicial, ST -- secundária tardia, SC -- sem caracterização); FV: Forma de Vida (Ep - Epífitas; A - Árvores; At - Arbusto; Li - Liana; H - Herbácea). *Espécies implantadas que não sobreviveram.

Fonte: Santos (2019). 


\subsection{Coleta e análise dos dados}

A coleta da serapilheira foliar nas áreas de estudos constitui-se de material recémcaído no solo. As amostras foram encaminhadas ao laboratório da Universidade Estadual de Mato Grosso do Sul (UEMS), inseridas em sacos de papel devidamente identificados e submetidas à secagem em estufa a $65^{\circ} \mathrm{C}$ por 96 horas. Posteriormente, pesou-se 10 gramas de serapilheira das respectivas áreas em balança de precisão e acrescentadas em cada litterbag. Foram alocados, aleatoriamente sobre a superfície do solo, 20 litterbags com malha de $4 \mathrm{~mm}$, área de $25 \times 25 \mathrm{~cm}$ e 1,5 cm nos dois sistemas agroflorestais. A retirada das amostras ocorreu aos 30,60, 90 e 120 dias, removendo-se 5 amostras por área para avaliar a taxa de decomposição no decorrer de junho a outubro de 2019.

Após a coleta, os litterbags foram encaminhados ao laboratório e com o auxílio de um pincel retirou-se o excesso de solo, matéria orgânica e alguns organismos vivos presentes na parte externa dos litterbags como formigas, cupins e besouros aderidos na parte exterior dos litterbags. A serapilheira foi removida dos litterbags e alocada em sacos de papel para secagem em estufa a uma temperatura de $65^{\circ} \mathrm{C}$ por um período de 72 horas. Ao término, a fração foliar foi pesada em uma balança de precisão para quantificação da massa foliar remanescente.

A quantificação da massa remanescente da serapilheira foi realizada de acordo com a seguinte fórmula:

Massa remanescente $(\%)=($ massa final $/$ massa inicial $) \times 100$

Após o cálculo da massa remanescente ao longo do período, a Constante de decomposição $(k)$ foi calculada, segundo o modelo exponencial ajustado, conforme Olson (1963):

$X=X_{0} \cdot e^{-k t}$

Onde, $\mathrm{X}$ : quantidade de matéria seca remanescente após um período de tempo $\mathrm{t}$ (dias); $\mathrm{X}_{0}$ : peso do material seco inicial no tempo zero ( $\left.\mathrm{t}=0\right)$; e $k$ : constante de decomposição diária. 
Com base nos termos dessa equação, foi mensurado o cálculo da constante de decomposição, representado abaixo:

$-k=\ln \left(\mathrm{X} / \mathrm{X}_{0}\right) / \mathrm{t}$

O tempo de meia vida ( $\mathrm{t} 1 / 2$ ), é usado para estimar o tempo necessário para que metade da fração inicial da serapilheira se decomponha por completo nos litterbags. De acordo com Rezende et al. (1997), ele é obtido por meio da seguinte equação:

$\mathrm{t}^{1} 1 / 2=\ln (2) / k$

Em que, $\mathrm{K}$ consiste na decomposição, mensurada pela fórmula anterior. Após a obtenção dos dados, utilizou-se a análise de variância (ANOVA).

Foi realizada a correlação linear simples de Pearson $(r)$ entre a massa remanescente foliar da serapilheira e as variáveis ambientais (precipitação e temperatura). A correlação de Pearson possui que valores variam de -1 a 1 , sendo catalogada segundo Callegari-Jacques (2003), da seguinte forma: 0,00 a 0,30: correlação fraca; 0,30 a 0,60: correlação moderada; 0,60 a 0,90: correlação forte; 0,90 a 1: correlação muito forte. As análises foram efetivadas com o auxílio do editor Microsoft Excel.

As variáveis de precipitação e temperatura utilizadas compreendem ao período de junho a outubro de 2019. Os dados climáticos da área de estudo foram obtidos pelo satélite Tropical Rainfall Measuring Mission (TRMM) da NASA e disponibilizados pelo portal do Agritempo com o código TRMM. 2328 (AGRITEMPO, 2020).

O clima do município de Pedro Gomes é classificado como tropical savânico úmido (AW), com período seco de 3 a 5 meses durante o inverno e o verão chuvoso. A pluviosidade anual varia de 1.000 a $1.500 \mathrm{~mm}$ e as temperaturas médias anuais oscilam de $20^{\circ} \mathrm{C}$ a $28^{\circ} \mathrm{C}$ (MATO GROSSO DO SUL, 2015). Na figura 2 é possível observar a variabilidade climática sazonal da temperatura e precipitação para o período experimental (25/06/2019 - 25/10/2019). 
Figura 2 - Precipitação acumulada e temperatura média da área de estudo no decorrer dos meses de junho a outubro de 2019

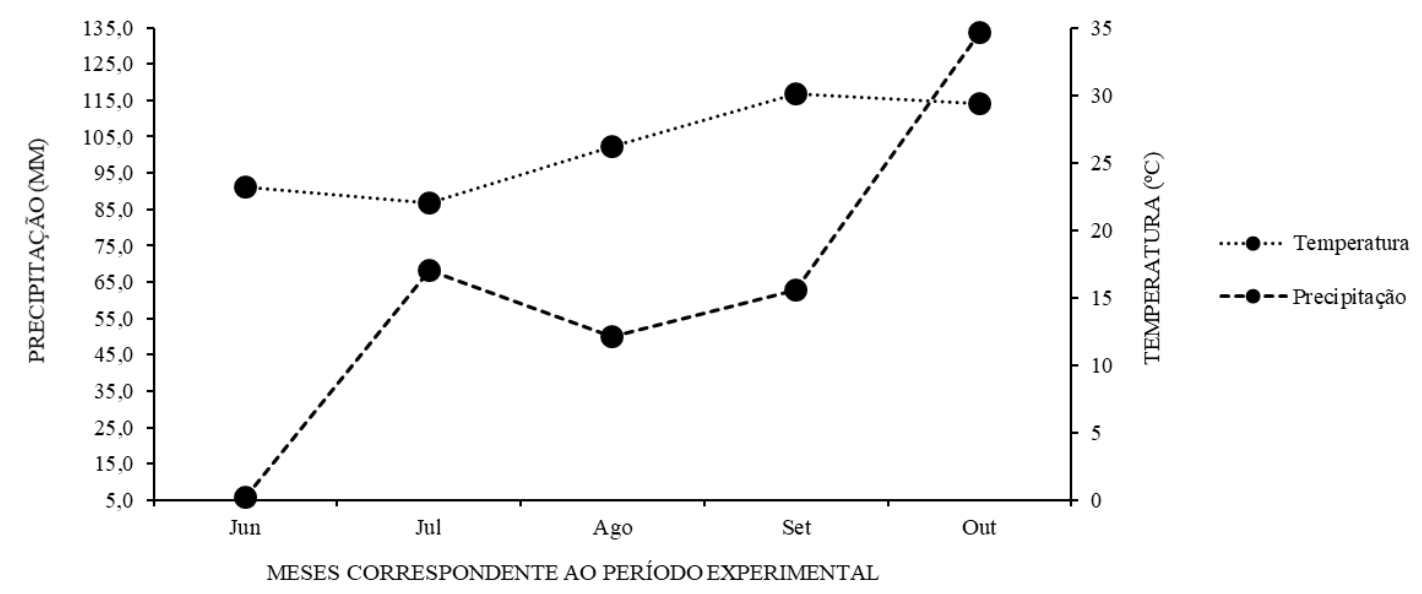

Fonte: Adaptado dos dados do Agritempo (2020).

\section{RESULTADOS E DISCUSSÕES}

O SAF1 aos 30 dias apresentou queda de apenas $0,88 \%$ e manteve-se estabilizado, com poucas variações no decorrer das avaliações, perdendo apenas $10,9 \%$ de massa foliar ao final dos 120 dias, perfazendo 89,10\% (Figura 3). É perceptível que o SAF2 apresentou maiores perdas de massa foliar no decorrer do período de avaliação, desde a fase inicial, representado uma queda de $16,78 \%$ da massa foliar aos 30 dias. Aos 60 dias houve uma queda de $46,95 \%$, perfazendo $53,05 \%$ da massa remanescente. Observa-se que dos 60 aos 90 dias houve pouca variação entre eles, entretanto, destaca-se uma perda de $41,85 \%$ de massa foliar com relação ao valor inicial, perfazendo $58,15 \%$ do total.

Figura 3 - Massa foliar remanescente da serapilheira nas áreas de SAF1 e SAF2 durante o período de avalição

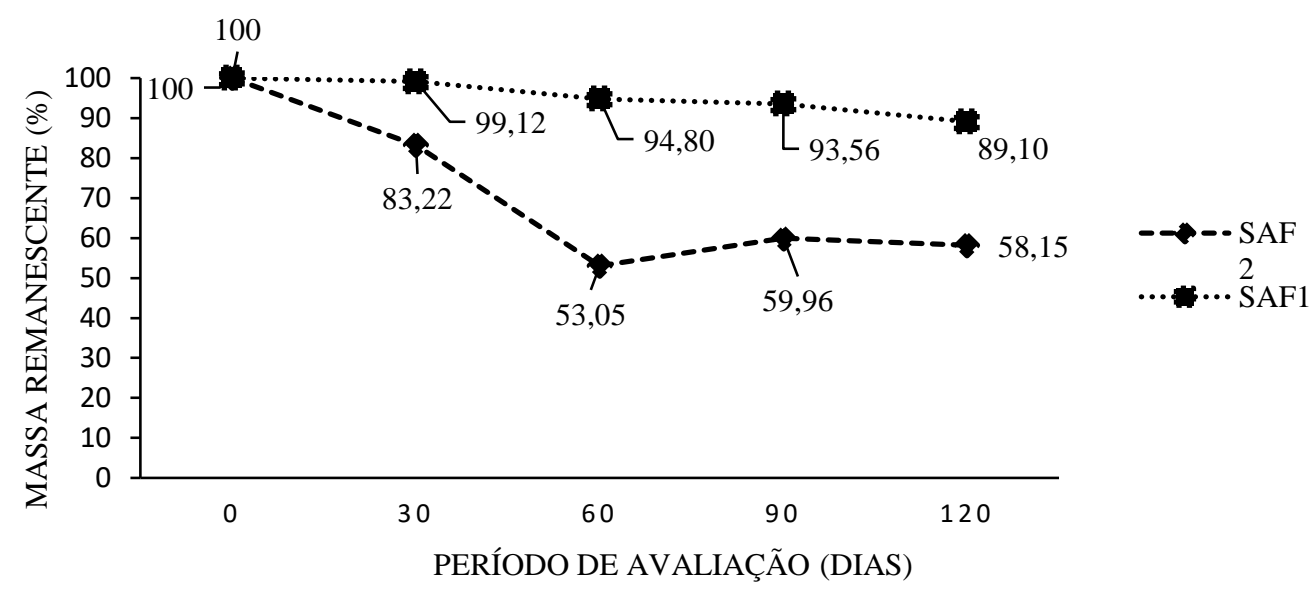

Fonte: Autoria própria. 
No estudo de Silva et al., (2014) em sistemas florestais no sudeste da Bahia observou-se que nos primeiros meses de experimento (julho e agosto) a massa foliar remanescente de uma floresta nativa apresentou redução de 17\%, enquanto nas áreas plantadas a degradação da massa foliar ocorreu com maior intensidade somente no último mês do experimento, atingindo redução de $18 \%$.

As perdas de massa foliar geralmente são maiores nos primeiros meses de implantação e podem estar relacionadas com o fato de que nos períodos iniciais a matéria orgânica menos resistente pode se desprender dos litterbags com maior facilidade, restando apenas matéria com maior resistência (SILVA, 2009; GRUGIKI et al., 2017). A perda mais acelerada pôde ser constatada para o SAF2, além da maior perda de massa foliar final.

O resultado do presente estudo pode ser explicado pela composição vegetal dos sistemas agroflorestais, que interfere na qualidade e diversidade do material foliar, fechamento do dossel, bem como demais características internas as áreas que propiciam microclima favorável e, consequentemente, melhores condições de umidade do solo, favorecimento da atividade dos organismos do solo, entre outros. O SAF2, que apresenta uma composição de espécies mais diversificada, dossel fechado e com poucas clareiras, destacou-se positivamente quanto à perda da massa foliar mais acentuada, enquanto que o SAF1 simplificado, composto por duas espécies e com condições opostas ao SAF2, apresentou baixa perda de massa foliar e pouquíssima variação entre os intervalos de tempo.

Sistemas agroflorestais biodiversos são mais interessantes do ponto de vista da restauração ecológica, trazendo inúmeros benefícios ambientais como a melhoria do solo, microclima, ciclagem de nutrientes, resgate da fauna, entre outros. Além disso, propiciam uma variedade de recursos ao longo do ano, a depender das espécies a serem escolhidas para compor os arranjos, fortalecendo a segurança alimentar e econômica do produtor rural.

Observando-se as Figura 4 e 5, embora as condições de temperatura e precipitação sejam iguais para ambas, é nítida a diferença do padrão de decomposição da massa foliar entre os SAFs, fortalecendo a discussão supracitada. O SAF1 simplificado apresenta baixa quantidade de massa foliar no solo, podendo vir a diminuir o aporte de nutrientes e, consequentemente, a atividade de decompositores, diferentemente do SAF2 biodiverso, no qual foi possível observar nas coletas dos litterbags a presença de fauna epigeica no solo, 
como cupins e besouros. A riqueza e diversidade desses organismos, bem como de organismos microscópicos (fungos e bactérias), influenciam na decomposição da serapilheira e possuem papel fundamental nos processos de ciclagem de nutrientes e estruturação do solo, atuando principalmente em áreas que são mais diversificadas, atrativas e palatáveis para esses organismos (NETO, 2017; MOÇO, 2010).

Figura 4 - Precipitação acumulada, temperatura média e massa remanescente do sistema agroflorestal simplificado (SAF1) no decorrer do período experimental

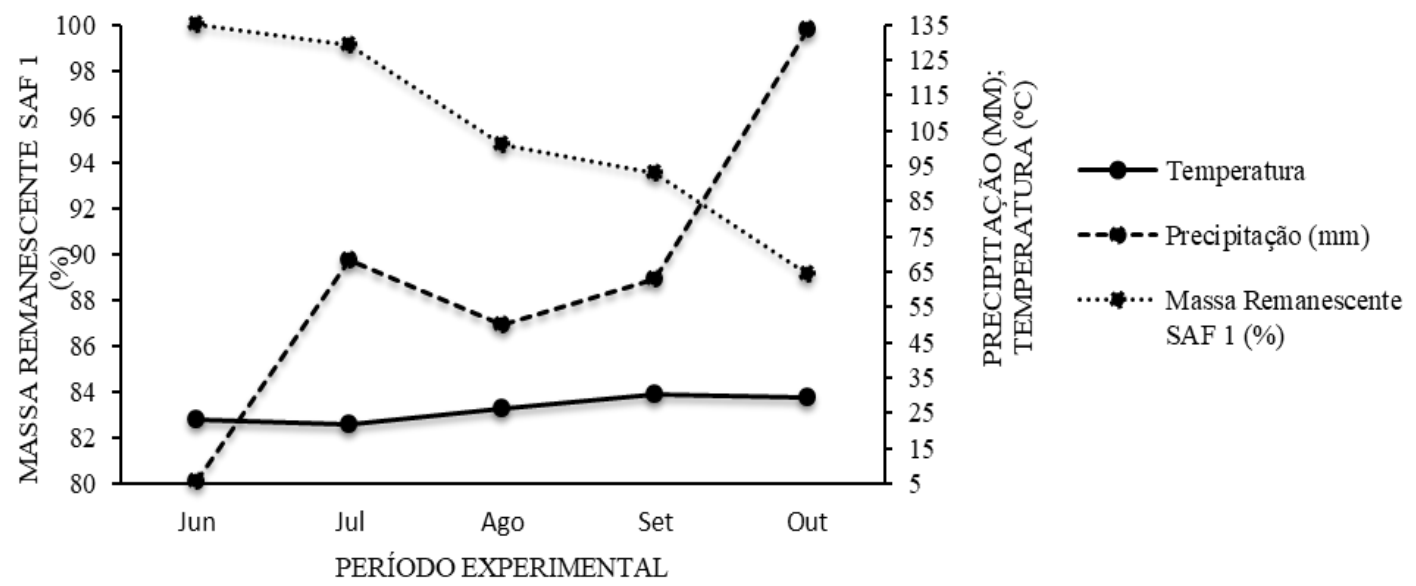

Fonte: Autoria própria.

Figura 5 - Precipitação acumulada, temperatura média e massa remanescente do sistema agroflorestal biodiverso (SAF2) no decorrer do período experimental

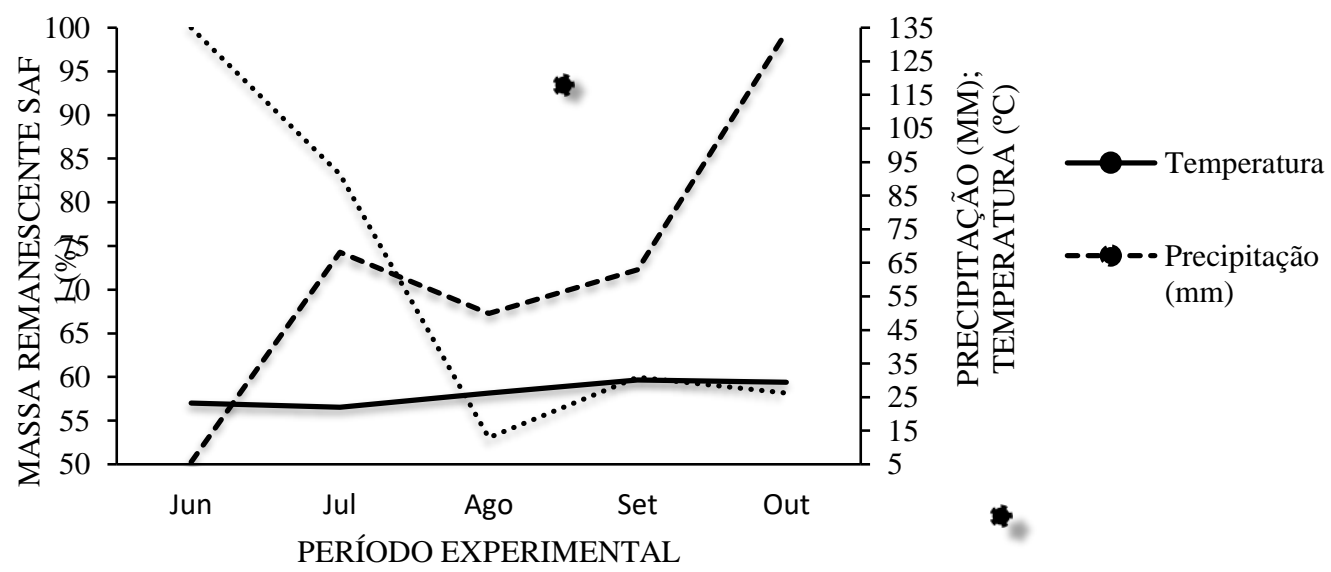

Fonte: Autoria própria.

A decomposição da serapilheira é a principal fonte para ciclagem de nutriente no solo, porém esse processo depende de vários fatores abióticos que envolvem as condições climáticas do local como a temperatura, que influencia diretamente na velocidade da decomposição fazendo com que ocorram reações químicas $e$ as atividades dos decompositores, e a precipitação tem ação na desestruturação de materiais através dos 
pingos de chuva e tem influência direta na umidade do solo. Esses elementos climáticos são os principais reguladores da variação no aporte de serapilheira e em sua velocidade de decomposição (BIANCHI; SCORIZA; CORREIA, 2016).

Com base nos valores encontrados para a Constante de decomposição $(k)$ e Tempo de meia vida (t 1/2), percebe-se que o SAF2 apresentou decomposição mais acelerada $\left(0,003 \mathrm{~g} \mathrm{~g}^{-1} \mathrm{dia}^{-1}\right)$ e menor tempo de meia vida (227 dias).

\begin{tabular}{|c|c|c|}
\hline Áreas de estudo & $\begin{array}{l}\text { Constante de } \\
\text { decomposição } \\
(k)\end{array}$ & Tempo de meia vida (t $1 / 2)$ \\
\hline & $\left(g^{-1} \mathrm{dia}^{-1}\right)$ & (dias) \\
\hline SAF1 & 0,001 & 772,60 \\
\hline SAF2 & 0,003 & 227,32 \\
\hline
\end{tabular}

Fonte: Os autores.

A constante de decomposição representa a velocidade de decomposição, já o tempo de meia vida, trata-se do tempo médio necessário para que a quantidade da massa foliar se reduza à metade (SANDES-GUIMARÃES, 2013).

Em estudo realizado por Grugiki et al. (2017) foi constatado que a decomposição ocorreu com maior velocidade em áreas com quantidade mais abundante de serapilheira e com diferentes espécies vegetais, consequentemente apresentando maior porção de matéria orgânica e de organismos decompositores. É possível que esse seja o caso do SAF2, em vista de sua caracterização e condições anteriormente citadas.

Na Tabela 4 estão dispostos os valores obtidos para a correlação de Pearson entre as variáveis de precipitação e temperatura durante o período de estudo e a decomposição do material remanescente entre os meses de junho a outubro de 2019.

Tabela 4 - Correlação de Pearson $(r)$ entre as variáveis climáticas em relação à massa foliar remanescente de dois sistemas agroflorestais, município de Pedro Gomes - MS

\begin{tabular}{lll}
\hline Fatores & Massa remanescente (\%) & $\begin{array}{l}\text { Massa remanescente (\%) } \\
\text { SAF 2 }\end{array}$ \\
& SAF 1 & $-0,7723$ \\
\hline Temperatura & $-0,8889$ & $-0,6170$ \\
Precipitação & $-0,8356$ & \\
\hline
\end{tabular}

Fonte: Os autores. 
Ao observar os resultados da Tabela 4, nota-se que a massa remanescente do SAF2 indica que houve uma forte correlação negativa com a temperatura $(-0,7723)$, ou seja, a temperatura teve influência direta na decomposição da massa foliar da serapilheira e quanto maior a temperatura menor a massa remanescente. O mesmo ocorreu com a precipitação, que demostrou forte correlação negativa $(-0,6170)$, evidenciando que as chuvas influenciam na dinâmica de decomposição.

No SAF1 ambas variáveis climáticas também apresentaram forte associação com a redução de massa da serapilheira, sendo maior a correlação com a temperatura $(-0,8889)$ em detrimento a precipitação $(-0,8356)$.

Ao avaliar a influência meteorológica sobre a serapilheira Brun et al. (2001), encontraram baixas correlações para os elementos climatológicos (precipitação, temperatura, umidade relativa, velocidade do vento e evapotranspiração) em todos os estádios sucessionais da área de estudo, concluindo que a deposição de serapilheira é pouco afetada pela precipitação, sendo mais influenciada pela temperatura. Porém, em estudo realizado por Siqueira et al. (2016), indicou que houve interferências dessas variáveis climáticas. Para Schumacher et al. (2013), a principal fração formadora da serapilheira (folhas) não apresentou correlação significativa com variáveis climatológicas, o mesmo foi observado por outros autores (BAUER; FUHR; SCHIMTT, 2017; PIRES et al., 2005; SILVA et al., 2014). Assim, embora tenha algumas divergências nos resultados obtidos pelos estudos, é consenso que os aspectos meteorológicos são importantes variáveis abióticas capazes de impactar na dinâmica de decomposição da serapilheira, apesar de não serem os únicos fatores ambientais.

\section{CONCLUSÃO}

O SAF2 (biodiverso) apresentou menor massa foliar remanescente e maior velocidade de decomposição, em virtude das condições internas de sua área, que favoreceram a decomposição, o que pode influenciar diretamente na disponibilização de nutrientes ao solo e ao retorno dos mesmos para o sustento da vegetação. Para ambas as áreas, a temperatura e precipitação influenciaram fortemente na decomposição foliar da serapilheira, nesse sentido, os elementos climatológicos são essenciais para a taxa de decomposição. 
Os Sistemas Agroflorestais biodiversos são considerados uma ótima alternativa à recuperação de áreas degradadas, promovendo benefícios ecológicos com a prestação de serviços ambientais, bem como ganhos socioeconômicos, com a diversificação de produtos que auxiliam na segurança alimentar e geração de renda ao produtor rural.

O estudo da decomposição da serapilheira foliar mostrou-se eficaz na compreensão da velocidade de decomposição e perda de massa remanescente, entretanto, para averiguar o sucesso de sistemas implantados com enfoque na restauração de áreas degradadas é importante também analisar outros fatores para a obtenção de uma visão ambiental sistêmica e assim subsidiar futuras tomadas de decisão para atingir o êxito dessas áreas, no que tange ao resgate de processos ecológicos e autoperpetuação do ecossistema.

\section{REFERÊNCIAS}

AGRITEMPO. Sistema de Monitoramento agrometeorológico. Disponível em: https://www.agritempo.gov.br/agritempo/jsp/Estatisticas/index.jsp?siglaUF=MS. Acesso em: 23 abr. 2018.

AMADOR, D. B. Restauração de ecossistemas com sistemas agroflorestais: restauração de ecossistemas naturais. Botucatu, SP: Fundação de Estudos e Pesquisas Agrícolas e FlorestaisFEPAF, 2003.

ANDRADE, A. G; TAVARES, S. R. L.; COUTINHO, H. L. C. Contribuição da serrapilheira para recuperação de áreas degradadas e para manutenção da sustentabilidade de sistemas agroecológicos. Embrapa Solos-Artigo em periódico indexado (ALICE), 2003.

BAUER, D., FÜHR, C. S.; SCHMITT, J. L. Dinâmica do acúmulo e decomposição de serapilheira em Floresta Estacional semidecidual subtropical. Pesquisas Botânica, 70, 1-11. 2017. Disponível em: http://www.anchietano.unisinos.br/publicacoes/botanica/botanica70/013.pdf. Acesso em: abr. 2018.

BIANCHI, M. O; SCORIZA, R. N; CORREIRA, M. E. F. Influência do clima na dinâmica de serrapilheira em uma floresta estacional semidecidual em Valença, RJ, Brasil. Revista Brasileira de Biociências, v. 14, n. 2, 2016. Disponível em: http://www.ufrgs.br/seerbio/ojs/index.php/rbb/article/view/3377 Acesso em: abr. 2018.

BRASIL. Lei no 12.651, de 25 de maio de 2012 - Dispõe sobre a proteção da vegetação nativa. Brasília, 25 de maio de 2012.

BRUN, E. J.; SCHUMACHER, M. V.; SPATHELF, P. Relação entre a produção de serapilheira e variáveis meteorológicas em três fases sucessionais de uma Floresta Estacional Decidual no Rio Grande do Sul. Revista Brasileira de Agrometeorologia, Piracicaba, v. 9, n. 2, p. 277 - 285, 2001. CALLEGARI-JACQUES, S. M. Bioestatística: princípios e aplicações. Porto Alegre: Artmed, 2003. $255 \mathrm{p}$. 
CUNHA, N. R. S. et al. A intensidade da exploração agropecuária como indicador da degradação ambiental na região dos Cerrados, Brasil. Revista de Economia e Sociologia Rural, v. 46, n. 2, p. 291-323, 2008. https://doi.org/10.1590/S0103-20032008000200002

GONÇALVES, R. C. et al. Manual de Heveicultura para a região sudeste do Estado do Acre. Embrapa Acre - Documentos (INFOTECA-E), 2013.

GRUGIKI, M. A. et. al. Decomposição e atividade microbiana da serapilheira em coberturas florestais no sul do Espírito Santo. Floresta e ambiente, v. 24, e20150189, 2017. https://doi.org/10.1590/2179-8087.018915

HERNANI, L. C; SOUZA, L. C. F; CECCON, G. Consorciação de culturas. Agência Embrapa de Informação Tecnológica, 2019.

INSTITUTO BRASILEIRO DE GEOGRAFIA E ESTATISTICA (IBGE). Database 2019. Disponível em: $\quad$ https://mapas.ibge.gov.br/bases-e-referenciais/bases-cartograficas/malhas-digitais.html. Acesso em: 31 abr. 2020a.

INTITUTO BRASILEIRO DE GEOGRAFIA E ESTATISTICA (IBGE). Pedro Gomes, MS. 2019. Disponível em: https://cidades.ibge.gov.br/brasil/ms/pedro-gomes/panorama. Acesso em: 31 abr. $2020 b$.

LAMÔNICA, K. R.; BARROSO, D. G. Sistemas agroflorestais: aspectos básicos e recomendações. Niterói: Programa Rio Rural. Manual Técnico n. 7). 2008. 12 p.

MATO GROSSO DO SUL. Estudo da dimensão territorial do estado de Mato Grosso do Sul: regiões de planejamento. Mato Grosso do Sul: Secretaria de Estado de Meio Ambiente e Desenvolvimento Econômico, 2015.

MINISTÉRIO DO MEIO AMBIENTE (MMA). Recuperação de Áreas Degradadas, 2019. Disponível em: https://www.mma.gov.br/informma/item/8705-recupera\%C3\%A7\%C3\%A3o-de-\%C3\%A1reasdegradadas. Acesso em: 13 set. 2019.

MOÇO, M. K. S. Atributos biológicos em solo e serapilheira sob sistemas agroflorestais de cacau e outras coberturas vegetais. 2010. 100f. Tese (Doutorado em Produção Vegetal) Universidade Estadual do Norte Fluminense Darcy Ribeiro, Rio de Janeiro, 2010.

NETO, P. R. M. S. Processo de decomposição da serrapilheira atuando como mecanismo de facilitação. 2017. 49f. Dissertação (Mestrado em Ecologia) - Centro de Biociências, Universidade Federal do Rio Grande do Norte, Natal, 2017.

PEREIRA, V. A. et al. Cultura da Seringueira em Goiás. Embrapa Cerrados. 2002. Disponível em: https://www.infoteca.cnptia.embrapa.br/bitstream/doc/567490/1/p200279.pdf. Acesso em: 31 abr. 2020.

PIRES, L. A. et al. Produção, acúmulo e decomposição da serapilheira em uma restinga da llha do Mel, Paranaguá, PR, Brasil. Acta Botanica Brasilica, 173-184, 2005. https://doi.org/10.1590/S0102$\underline{33062006000100016}$

QUANTUM GEOGRAPHIC INFORMATION SYSTEM - QGIS. Software livre que permite a visualização, edição e análise de dados georreferenciados. Fundação Geoespacial de Código Aberto. Versão 2.18.0. 
OLSON, J. S. Energy storage and the balance of producers and decomposers in ecological systems. Ecology, v. 44, n. 22, p. 322- 330, 1963. https://doi.org/10.2307/1932179

REZENDE, J. P.; GARCIA, Q. S.; SCOTTI, M. R.; LEITÃO, M. M. Decomposição de folhas de Dalbergia nigra e de Eucalyptus grandis incubadas em terra de mata e de eucaliptal. In: SIMPÓSIO NACIONAL DE RECUPERAÇÃO DE ÁREAS DEGRADADAS: DO SUBSTRATO AO SOLO, 3., 1997. Anais [...]. Ouro Preto: SOBRADE; UFV; DEF, p. 136-143, 1997.

SANDES-GUIMARÃES, L. V. S. Meia-vida da ERA. Revista de Administração de Empresas. 2013. Disponível em: https://rae.fgv.br/sites/rae.fgv.br/files/arquivos/meia-vida raerevista de administracao de empresas.pdf. Acesso em: 31 abr. 2020.

SANTOS, M. Enriquecimento e florística do componente arbóreo de um sistema agroflorestal em área de cerrado sul mato-grossense, Brasil. 2019. Trabalho de Conclusão de Curso (Bacharelado em Gestão Ambienta) - Universidade Estadual de Mato Grosso do Sul, Coxim, 2019.

SCHUMACHER, M. V. et al. Produção e decomposição de serapilheira em um povoamento de Eucalyptus urophylla x Eucalyptus globulus maidenii. Cerne, v. 19, n. 3, p. 501-508, 2013. https://doi.org/10.1590/S0104-77602013000300018

SILVA, H. F. et al. Decomposição de serapilheira foliar em três sistemas florestais no Sudoeste da Bahia. Revista Brasileira de Biociências, v. 12, n. 3, 2014. Disponível em http://www.ufrgs.br/seerbio/ojs/index.php/rbb/article/view/2818/1254. Acesso em: abr. 2018.

SILVA, L. V. B. Estudos ecológicos sobre a decomposição de serrapilheira em vegetação de cerrado. 2009. 71f. Dissertação (Mestrado em Ciências Biológicas) - Universidade Federal de Uberlândia, Uberlândia, 2009.

SIQUEIRA, T. M. et al. Influências climáticas na produção de serapilheira em um cerradão em Prata-MG, 2016. Biotemas, v. 29, n. 2, p. 7-15, 2016. https://doi.org/10.5007/2175$\underline{7925.2016 \mathrm{v} 29 \mathrm{n} 2 \mathrm{p} 7}$

SPERANDIO, H. V. et al. Emprego da serapilheira acumulada na avaliação de sistemas de restauração florestal em Alegre-ES. Floresta e Ambiente, v. 19, n. 4, p. 460-467, 2012.

https://doi.org/10.4322/floram.2012.060 